\title{
SAFETY IMPROVEMENTS OF NON-SPARKING AND INCREASED SAFETY MOTORS
}

\author{
Jussi Rautee, M.Sc. (Eng.) \\ ABB Oy / Machines \\ P.O. Box 186 \\ FIN-00381 Helsinki \\ Finland
}

jussi.rautee@fi.abb.com

\author{
Frank Lienesch, Dr. Ing. \\ PTB \\ Bundesallee 100 \\ D-38116 Braunschweig \\ Germany
}

frank.lienesch@ptb.de

\author{
Tom Liew, B.Sc. (1st Hons), FIET \\ Shell Motiva \\ 12th Floor PNT, 700 Milam \\ Houston \\ TX 77002, USA
}

tom.liew@motivaent.com

\begin{abstract}
Safety has always been one of the most important topics of discussion within chemical, oil and gas industry organizations. Recent developments aiming to improve the safety of electrical machines used in hazardous areas include the adoption of risk assessment requirements for increased safety and non-sparking motors by the IEC 60079-7:2001/:2006 and IEC 60079-15:2005 standards. These requirements oblige manufacturers to prove their designs by testing, or to equip their products with special accessories if the risk levels exceed acceptable limits. As the risk assessment procedure requires input from both the manufacturer and end user, it also promotes collaboration in the interest of safety.
\end{abstract}

Index Terms - Ex e motors, Ex $\mathrm{n}$ motors, sparking, explosive gases, IEC 60079-7, IEC 60079-15, gas environment testing, risk assessment.

\section{INTRODUCTION}

The first part of this paper will examine the incidents involving high voltage motors in hazardous areas which led to efforts to develop the standards. The response of the relevant authorities and actions by end users and manufacturers are also described.

The mechanisms within motors which can give rise to rotor and stator sparking are examined, along with the methods available to manufacturers to prevent sparking and make their designs safe.

A description of the way in which the standards have evolved is followed by a detailed examination of the current requirements, including the risk factor tables.

The next section explores practical aspects of gas environment testing, which remains the only way to verify that a given design is completely safe.

The final main part of the paper examines the options available under the standards: risk assessment, provision for pre-purging, and gas environment testing.

Please note that throughout this paper 'Ex n' should be taken as referring to 'Ex $n A$ ', i.e. the requirements for nonsparking equipment as applied to motors.

\section{BACKGROUND EVENTS AND FACTORS}

\section{A. Serious Incidents Involving Hazardous Area Motors}

The initial impetus which led to the development of the risk assessment requirements for Ex e and Ex $\mathrm{n}$ motors specified in standards IEC 60079-7:2001/:2006 and IEC 60079-15:2005 can be traced back to incidents during the 1980 s and '90s involving these types of motor operating in hazardous areas.
The development process will be described by examining incidents which occurred in the UK, together with the consequent actions on the part of the authorities and end users. The UK can be considered a good example for this purpose as there is a large installed base of Ex e and Ex $n$ motors operating in hazardous areas in and around the North Sea oil and gas fields, and the regulatory environment in the UK is well developed.

The situation in the early 1980s was regulated by "old approach" directives. Rather than imposing general safety requirements, these directives referred directly to the standards. The standards in question were EN 50014 and EN 50019 for increased safety and EN 50021 for nonsparking machines.

In November 1995 the UK Health and Safety Executive (HSE) issued an Operational Circular [1] which reported that in the period $1984-1992$ there had been six incidents in the UK involving high voltage explosion-protected motors. Information on the incidents from the HSE Circular and a report published in 1990 by motor manufacturers [2] is collected in Table I.

The HSE report noted that all the incidents in the UK were understood to have concerned Ex $\mathrm{N}$ motors, but that in Germany similar concerns had been raised about Exe motors, too.

\section{B. Response Of The Authorities}

Following the incidents, the UK Department of Energy issued Safety Notices to users of the type of equipment involved. Safety Notices No. 3, 11, 14, and 21 of 1989, for example, provided advice to users of HV Ex e and Ex N motors concerning circulating currents in the motor enclosures and electrical discharges on the stator windings. A Safety Notice issued in October 1990 [3] contained the following additional recommendations to qualify those in British Standard Code of Practice BS 5345:

1. For Ex e, Ex $\mathrm{N}$ and Ex $\mathrm{p}$ motors rated at or above 3 $\mathrm{kV}$, any possibility of gas ingress to the motor enclosure from common systems should be eliminated; manufacturers' recommendations with regard to circulating currents in large unitconstruction motors (e.g. fitting of bonding straps) should be implemented (does not apply to circulating currents in external components of Ex $p$ motor enclosures).

2. Ex e motors rated at or above $3 \mathrm{kV}$ located in Zone 1 areas should be pressurized, and in future such motors rated above $3 \mathrm{kV}$ should not be selected for Zone 1 areas.

3. Ex e and Ex $\mathrm{N}$ motors rated between $3 \mathrm{kV}$ and 11 
$\mathrm{kV}$ situated in Zone 2 areas should not be started if there is a possibility of an explosive atmosphere within the motor enclosure.

4. Ex N motors rated above $11 \mathrm{kV}$ and located in Zone 2 areas should be pressurized, and in future such motors should not be selected for Zone 2 areas.

TABLE I

INCIDENTS IN THE UK INVOLVING HV EXPLOSION-PROTECTED MOTORS, 1984-1992

\begin{tabular}{|c|c|c|c|}
\hline Year & Description & Voltage & Duty \\
\hline 1984 & $\begin{array}{l}\text { Sparking was observed } \\
\text { between a terminal box and } \\
\text { side plate during starting. No } \\
\text { explosion occurred and the } \\
\text { motor continued to operate. }\end{array}$ & $13.8 \mathrm{kV}$ & $\begin{array}{l}\text { Crude oil } \\
\text { pump }\end{array}$ \\
\hline 1985 & $\begin{array}{l}\text { Inspection of an 'in-service' } \\
\text { motor suggested that an } \\
\text { internal explosion had occurred. } \\
\text { The motor continued to } \\
\text { operate. The source of ignition } \\
\text { was not satisfactorily explained. }\end{array}$ & $11 \mathrm{kV}$ & $\begin{array}{l}\text { Gas } \\
\text { compressor }\end{array}$ \\
\hline 1988 & $\begin{array}{l}\text { A motor exploded during a start } \\
\text { up procedure. There was } \\
\text { evidence of electrical faults } \\
\text { within the stator winding. Most } \\
\text { of these faults were thought to } \\
\text { have occurred as the motor } \\
\text { exploded. }\end{array}$ & $11 \mathrm{kV}$ & $\begin{array}{l}\text { Gas } \\
\text { compressor } \\
\text { with } \\
\text { combined } \\
\text { lube oil } \\
\text { system }\end{array}$ \\
\hline 1989 & $\begin{array}{l}\text { A motor exploded on start up. } \\
\text { Bonding straps had been fitted. } \\
\text { Initial conclusions suggested } \\
\text { that ignition was due to an } \\
\text { electrical fault in the motor, but } \\
\text { the possibility of ignition due to } \\
\text { sparking, owing to interruption } \\
\text { of circulating currents in the } \\
\text { motor enclosure or } \\
\text { constructional parts, could not } \\
\text { be excluded. Nor could the } \\
\text { possibility of some other } \\
\text { electrical discharge } \\
\text { mechanism. }\end{array}$ & $13.8 \mathrm{kV}$ & $\begin{array}{l}\text { Gas } \\
\text { compressor } \\
\text { with } \\
\text { combined } \\
\text { lube oil } \\
\text { system }\end{array}$ \\
\hline 1991 & $\begin{array}{l}\text { A motor exploded during start } \\
\text { up. There was evidence of } \\
\text { motor faults which could have } \\
\text { resulted in sparking. }\end{array}$ & $\mathrm{N} / \mathrm{a}$ & $\mathrm{N} / \mathrm{a}$ \\
\hline 1992 & $\begin{array}{l}\text { On start up a small explosion } \\
\text { from the motor was heard and a } \\
\text { flash observed. The motor } \\
\text { started successfully and was } \\
\text { left running. Subsequent } \\
\text { investigation revealed slight } \\
\text { distortion of the motor cooler. }\end{array}$ & $11 \mathrm{kV}$ & $\begin{array}{l}\text { Gas } \\
\text { compressor } \\
\text { with common } \\
\text { oil/lube seal } \\
\text { system }\end{array}$ \\
\hline
\end{tabular}

N/a = information not available

In its 1995 Operational Circular [1] the HSE reported that it had commissioned ERA Technology Ltd, a contract research organization, to conduct research into the discharge activity occurring in $\mathrm{HV}$ machines, in particular to determine whether this activity could potentially cause incendive sparks.

The ERA study concluded that several of the discharge mechanisms found in the motors did have the potential to cause ignition of explosive atmospheres. Furthermore, the standards to which the machines had been made and certified were not adequate to ensure that they would remain non-incendive in all service conditions.

Although the ERA research could not entirely exclude discharge activity which could lead to ignition in machines rated below $3 \mathrm{kV}$, the HSE had no evidence that lower voltage machines had been the source of ignition of explosive atmospheres, and therefore did not propose any action in respect of existing machines rated below $3 \mathrm{kV}$.

The HSE's Information Document [1] listed factors likely to affect the probability of motors being incendive:

1. High voltage (stator discharge activity more likely in machines rated at $3 \mathrm{kV}$ or more)

2. High rotor currents (rotor bar-to-bar currents likely to be highest when machines started direct-on-line or plugged)

3. Contamination of $\mathrm{HV}$ insulation within the motor, especially in parts of the stator windings. Dependent on environmental conditions, ingress rate of ambient air and contaminants into the enclosure, time on site and total hours in operation, and effectiveness of maintenance to clean the motor and preserve insulation

4. Operational conditions (especially vibration and other factors likely to cause relative movement between rotor bars and rotor core)

5. Frequency of starting

The same document also provided criteria for setting priorities for risk assessment, as the HSE recognized that an individual organization could have thousands of Ex e and Ex $\mathrm{N}$ motors in service, of which very few might be at risk of providing a source of ignition.

\section{Actions By End Users}

Sources within a major end user have described the measures taken by the company in light of the incidents that occurred and subsequent official notices.

A series of internal meetings were held to identify the real problems in the petroleum industry, and to formulate practical solutions that could be implemented by all the operating companies within the group. The main outcome was the realization that motors driving centrifugal and screw compressors in hydrocarbon service are particularly vulnerable to gas ingress during the start sequence and hence, should not be of the Ex $n$ type. It was noted that the only instances of explosions involving HV motors had occurred in units driving such compressors.

In September 1994 the company issued the following list of recommended "actions that have to be taken to ensure safe plant operation" to its operating companies. This list summarizes the advice that had been given to the operating companies, with the date in parentheses indicating when the advice was first issued:

1. Bonding of enclosures for unit-construction machines in Zones 1 or 2 (February 1990)

2. Elimination of common vents (1991)

3. No HV Ex e motors in Zone 1, whether new or existing

4. Separation of motor lube oil from hydrocarbon compressor seal oil except for motors with pedestal bearings external to the motor enclosure (March 1990)

5. Install Ex $d$ or Ex $p$ motors for all HV centrifugal/screw hydrocarbon compressor drives in Zone 1, and for new HV centrifugal/screw compressor drives in Zone 2

6. Install automatic prestart purge for existing HV Ex $n$ or Ex e centrifugal/screw hydrocarbon compressor drives in Zone 2. Such purge should be maintained for continuous dilution if the automatic purge time is 
too long for quick-start requirements of standby units

7. Use double-seals for pumps in certain types of operation

8. Conduct winding-contamination checks on all HV units undergoing breakdown repairs, bearing changes, or mechanical condition checks

In addition to the steps taken by individual end users, end user organizations were also proactive. In 1995 the Londonbased Engineering Equipment and Materials Users Association (EEMUA) published a guide to risk assessment for HV Ex e and Ex $\mathrm{N}$ machines [4]. This includes decision trees to aid personnel tasked with assessing the risk associated with existing HV machines installed in potentially explosive atmospheres.

\section{Research By Manufacturers}

Naturally the motor manufacturers, for their part, also began to work urgently to determine the source of the sparking. They therefore undertook their own rotor and stator sparking tests, utilizing gas environments and techniques to visualize air gap sparking. One large manufacturer published high speed photographs showing sparking in its designs.

The manufacturers' work produced the following conclusions:

1. Stator sparking can occur at any time during motor operation. The risk is increased by transients from the network, surface contamination and ageing.

2. Rotor sparking results from the intermittent breaking of the contact between the rotor bars and core. It occurs during starting only, and is limited to the first sections of the rotor core.

\section{WHERE DOES SPARKING OCCUR IN MOTORS?}

\section{A. Stator}

Stator sparking consists of partial discharges (PDs) at the winding surface due to high potential differences, and it tends to occur while the motor is running. PDs can be defined as electrical discharges across part of the insulation between two electrodes - they do not bridge the whole of the gap between the electrodes. In rotating machines they are caused by the ionization of gas (in this case air) molecules in an electric field. The visible sparking that occurs is also referred to as a 'corona'.

The onset of a PD is defined by the partial discharge inception voltage. The critical voltage level depends only on the electrical field and can be very low. Ignition can only occur as a result of outer PDs, i.e. those which take place on the surface of the winding system and are therefore potentially in contact with an explosive atmosphere. Research [5] has shown that a PD level of $10 \mathrm{nC}$ is still safe for IIC gases. Inner PDs, by contrast, occur inside the insulation system and the charge level is measured in picocoulombs.

In order to prevent PDs, attention must be focused on the following issues:

1. Provision of effective stress grading - i.e. the use of semi-conductive tape to avoid high field strength differentials between adjacent points on the overhang. If stress grading is not used, a corona can occur at the point where the conductive tape ends, due to the significant difference in field strength at this point. The corona will, in turn, cause erosion of the conductive tape. See Fig. 1.

2. Adequate clearances - between phases, connections and coil ends, windings and the frame (at both ends), and windings and RTD cables. RTDs should be installed so as to provide direct contact with the frame; they should not be mounted on the overhang part of the winding system.

3. Routing of the cable connecting the terminal and windings. If it is in direct contact with the grounded enclosure a strong electrical field will occur at that point (see Fig. 2.)

4. If heating wire is used to provide anti condensation heating, it should not be mounted on the overhang part of the winding system.

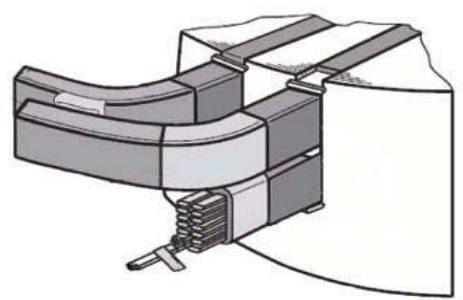

Fig. 1. Effective stress grading plays a crucial role in the prevention of PDs. Diagram source: [6].

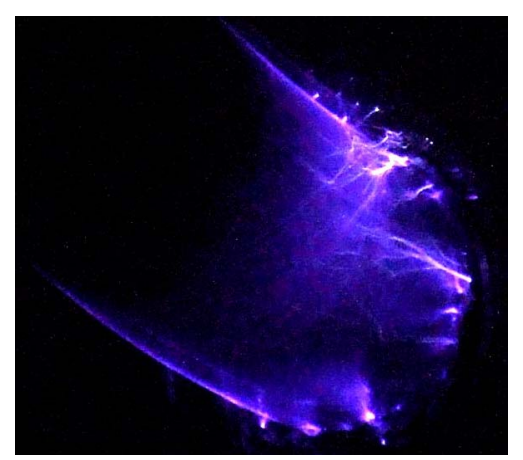

Fig. 2. Electrical discharges on the surface of a cable connecting the terminal and winding, at the point where it passes through the frame. (Photograph courtesy of test laboratory).

\section{B. Rotor}

Rotor sparking takes place during starting and occurs between the rotor bars and rotor core, especially in the vicinity of the first radial cooling ducts. It is caused by movement of the rotor bars, either within the slots or around the end of the core in the area where the bar is shaped. In most cases the movement is the result of angular and radial forces which act on the rotor during starting, and it interrupts current flow from the bars to the core, causing the sparking. Movement of the bars can also be caused by thermal bending on start-up, and by centrifugal forces acting on the bars.

Rotor bars are manufactured from copper or aluminum, while the core is iron. The superior conductivity of the bars means the majority of the current flows along the bar, but 
there is always some circulating (leakage) current from the bar to the core and it is this current which is interrupted by the movement of the bars.

Manufacturers can prevent rotor sparking by taking steps during design and production to ensure that the rotor bars are properly locked. In some cases the bars are swaged into the slot for this purpose, see Fig. 3.

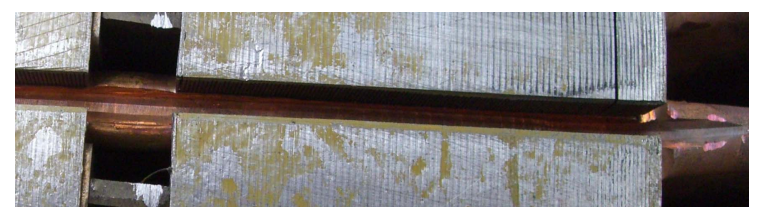

Fig. 3. Rotor bars can be swaged for a tight fit in the slot. (Photograph courtesy of Notified Body).

It is worth emphasizing that sparking takes place either within the stator, due to PDs, or within the rotor, due to movement of the bars on starting. It does not take place between the rotor and stator, i.e. across the air gap.

IEC 60079-7:2006 specifies [7] that a risk assessment is not necessary if the starting current is limited to $300 \%$ of the rated current. This condition is met by motors controlled with a VSD. In future, however, additional concerns could arise concerning bearing currents and stator sparking in motors controlled by MV VSDs.

\section{EVOLUTION OF STANDARDS}

The requirements for high voltage explosion-protected motors in hazardous areas in today's standards have been developed as consequence of the incidents described earlier. In its study for the UK Health and Safety Executive, ERA Technology Limited concluded in 1990 that several discharge mechanisms found in the motors did have the potential to cause ignition of explosive atmospheres, and that the standards to which the machines were made and certified were not adequate to ensure that they would remain non-incendive in all service conditions.

In 1997 CENELEC, the European Committee for Electrotechnical Standardization, published a prestandard, ENV 50269 [8], concerned with assessment and representative testing of HV machines. This applied to Ex e and Ex $n$ machines (and in part to Ex $p$ machines) over $1 \mathrm{kV}$, and it laid the basis for requirements with regard to equipotential bonding, stator winding discharge risk assessment factors, cage rotor sparking risk assessment factors, and gas testing. It was extended in 2000.

Subsequently, EN 50021:1999 10.1 [9] (Ex n) and EN 60079-15:2003 [10] (Ex n) referred to ENV 50269 in a note which stated that "rotating electrical machines should be in compliance with ENV 50269:1997. This is of particular importance where starting may be considered as part of normal operation." By contrast, EN 50019:2000 (Ex e) and EN 50016:2003 (Ex p) made no reference to ENV 50269.

With the publication of IEC 60079-7:2001 (Ex e) and IEC 60079-15:2005 (Ex n), the main requirements from ENV 50269 were integrated into the IEC standards. In the next step the IEC standards were accepted by CENELEC without modification (parallel voting process), leading to the publication of EN 60079-7:2003 and EN 60079-2005.

An important point is that manufacturers supplying the European market must comply with the requirements of Directive 94/9/EC (ATEX) [11] and can demonstrate compliance by following the harmonized standards. A standard is harmonized when it is listed in the "Official
Journal" of the European Commission. With the listing of a "new" standard the date of cessation of presumption of conformity of the superseded standard is also fixed. During the transitional period manufacturers can use both the "old" and "new" standards.

The ATEX Directive requires that manufacturers follow the "state of the art". This implies that they must go beyond the requirements of the standards to maximize safety. The presumption of conformity for EN 50019 ended in July 2006 and for EN 60079-15:2003 it will end in June 2008, at which point EN 60079-15:2005 will be followed.

Cessation of the presumption of conformity means that a manufacturer wishing to place a product on the European market has to follow the requirements for the stator and rotor risk assessment. Outside Europe (e.g. in certain Asian countries), the version of the standard that is in force may be determined by local legislation. As a result older versions of the standards may be in force, meaning that the risk assessment is not compulsory everywhere. In time, however, these countries will also 'catch up' with the main work of the IEC.

Meanwhile standard IEC 60079-07:2001 (Ex e) was updated as IEC 60079-7:2006 and adopted by CENELEC. This version is not presently listed in the Official Journal and is therefore not a harmonized standard under the ATEX Directive. Listing is expected during 2008, however, and so attention should be focused on this version.

IEC 60079-7:2006 [7] includes a new concept for stator risk assessment. The relevant table (reproduced here as Table V) is informative rather than normative because the content concerns the end user and ambient conditions, over which the manufacturer has no control. The reason for this change is that in most cases it is neither possible nor practical to specify the conditions before the motor is ordered from the manufacturer. Further problems occur when the end user performs renovation work and the ambient conditions in the plant are changed.

In parallel with the above change, the table was copied to IEC 60079-14 Ed. 4.0 [12], which is concerned with the design, selection, and erection of electrical Installations in explosive atmospheres, to underline the need for the end user to do the risk assessment for the stator.

A consequence of IEC 60079-7:2006 for manufacturers is that gas testing of the stator winding system $(>1 \mathrm{kV})$ is compulsory, and motors must be fitted with heating and prepurging devices to enable the end user to take the necessary action. Additionally, the rotor risk assessment table in the standard (reproduced here as Table VII) has been modified in order to create a separate category for insulated bars. This change is likely to cause considerable confusion in the market, however, as the standards do not specify what is meant by insulation.

Another critical point is the approach to the three different gas groups. In future Ex e and Ex $n$ motors will be marked with (for example) 'IIA', 'IIB' or 'IIC' instead of 'II'.

Due to the problems mentioned above, the standard for Ex $n$ machines will also be changed in the future. The concept of including the user in the stator risk assessment has already been included in the CD of IEC 60079-15. Discussion is presently focused on the compulsory voltage level for the stator test and whether the impulse test is necessary, i.e. whether the sinusoidal test alone would be sufficient.

The requirements with regard to equipotential bonding were adopted by IEC 60079-0 as "general requirements" and are therefore a principal requirement for all types of protection. Equipotential bonding ensures that all separate 
parts of the enclosure, including the cooling system on top of the machine, are electrically connected to ground. Additionally it provides a means of limiting the current flowing through different parts or segments of the enclosure in large machines. The factors giving rise to this current flow, which can amount to a number of amperes, include asymmetrical fields inside the machine (e.g. shaft voltage).

There are both positive and negative aspects to the way the standards have evolved. On the one hand new requirements have helped to reduce the potential risk associated with certain equipment. On the other, however, there are inconsistencies in the approaches to the two types of protection, Ex $\mathrm{n}$ and Ex e, resulting in confusion in the market. In addition, there can be considerable delays - up to a number of years - in implementing the standards in certain markets, and problems are caused not only by the equipment itself but also by the ambient conditions in which it is used.

\section{REQUIREMENTS SPECIFIED BY THE STANDARDS}

\section{A. Overview Of Current Requirements}

Tables II and III show, respectively, the current requirements for Ex $n$ motors per IEC 60079-15:2005 [13] and EN 60079-15:2005 [14], and Ex e motors under IEC 60079-7:2006 [7] and EN 60079-7:2007 [15].

TABLE II

REQUIREMENTS FOR NON-SPARKING MOTORS (IEC 60079-15:2005 AND EN 60079-15:2005) $^{a}$

\begin{tabular}{|l|l|l|}
\hline Voltage rating & Rotor & Stator \\
\hline$\leq 1 \mathrm{kV}$ & $\begin{array}{l}\text { Either gas environment } \\
\text { test or risk assessment, } \\
\text { possible need for } \\
\text { special measures. } \\
\text { Waived for machines } \\
\text { with rated power } \leq 100 \\
\mathrm{~kW} .\end{array}$ & $\begin{array}{l}\text { Either gas environment } \\
\text { test or risk assessment, } \\
\text { possible need for space } \\
\text { heater and special } \\
\text { measures. }\end{array}$ \\
\hline Over $1 \mathrm{kV}$ & \\
\hline
\end{tabular}
week or less.

IEC 60079-15 specifies that in the case of rotors where the bars are connected to end rings, precautions must be taken to guard against incendive arcs or sparks in normal operation - "in particular, the joints between the bars and short-circuiting rings shall be brazed or welded and compatible materials shall be used to enable high quality joints to be made."

TABLE III

REQUIREMENTS FOR INCREASED SAFETY MOTORS (IEC 60079-7:2006 AND EN 60079-7:2007)

\begin{tabular}{|c|c|c|}
\hline Voltage rating & Rotor & Stator \\
\hline$\leq 1 \mathrm{kV}$ & \multirow{2}{*}{$\begin{array}{l}\text { Either gas environment } \\
\text { test or risk assessment } \\
\text { possible need for } \\
\text { special measures. } \\
\text { Waived for machines } \\
\text { with starting current } \\
\leq 3 \mathrm{I}_{\mathrm{n}} \text {. }\end{array}$} & No requirements \\
\hline Over $1 \mathrm{kV}$ & & $\begin{array}{l}\text { Gas environment test } \\
\text { and need for space } \\
\text { heater and special } \\
\text { measures / risk } \\
\text { assessment. }\end{array}$ \\
\hline
\end{tabular}

${ }^{*}$ Type tests in accordance with standards IEC 60079-7:2006 / EN 60079-7:2007 shall be conducted for stators with rated voltage above $1 \mathrm{kV}$.

In addition, IEC 60079-7 requires equipotential bonding for machines with multi-section enclosures.

\section{B. Risk Assessment - Stator}

Table IV shows the stator winding risk assessment factors for Ex $\mathrm{n}$ motors. Further measures are required if the sum total of the factors determined by the table is greater than 6 , which is exceeded by most HV motors in practical applications.

TABLE IV

POTENTIAL STATOR WINDING DISCHARGE RISK ASSESSMENT FOR NON-SPARKING MOTORS (IEC 60079-15:2005)

\begin{tabular}{|c|c|c|}
\hline Characteristic & Value & Factor \\
\hline Rated voltage & $\begin{array}{l}>11 \mathrm{kV} \\
>6.6 \mathrm{kV} \text { to } 11 \mathrm{kV} \\
>3.3 \mathrm{kV} \text { to } 6.6 \mathrm{kV} \\
>1 \mathrm{kV} \text { to } 3.3 \mathrm{kV}\end{array}$ & $\begin{array}{l}6 \\
4 \\
2 \\
0\end{array}$ \\
\hline $\begin{array}{l}\text { Average starting } \\
\text { frequency in service }\end{array}$ & $\begin{array}{l}>1 / \text { hour } \\
>1 / \text { day } \\
>1 / \text { week } \\
\leq 1 / \text { week }\end{array}$ & $\begin{array}{l}3 \\
2 \\
1 \\
0\end{array}$ \\
\hline $\begin{array}{l}\text { Time between detailed } \\
\text { inspections (see IEC } \\
60079-17 \text { ) }\end{array}$ & $\begin{array}{l}>10 \text { years } \\
>5 \text { to } 10 \text { years } \\
>2 \text { to } 5 \text { years } \\
<2 \text { years }\end{array}$ & $\begin{array}{l}3 \\
2 \\
1 \\
0\end{array}$ \\
\hline $\begin{array}{l}\text { Degree of protection (IP } \\
\text { code) }\end{array}$ & $\begin{array}{l}<\text { IP44 }{ }^{\mathrm{a}} \\
\text { IP44 and IP54 } \\
\text { IP55 } \\
>\text { IP55 }\end{array}$ & $\begin{array}{l}3 \\
2 \\
1 \\
0 \\
\end{array}$ \\
\hline Environmental conditions & $\begin{array}{l}\text { Very dirty and wet }{ }^{b} \\
\text { Coastal outdoor }{ }^{c} \\
\text { Outdoor } \\
\text { Clean and dry indoor }\end{array}$ & $\begin{array}{l}4 \\
3 \\
1 \\
0\end{array}$ \\
\hline \multicolumn{3}{|c|}{$\begin{array}{l}\text { a Only in clean environments and regularly serviced by trained } \\
\text { personnel, see } 6.6 .1 \text {. (IEC 60079-15:2005) } \\
\text { b "Very dirty and wet" locations include those that may be } \\
\text { subjected to deluge systems or comprise open deck on } \\
\text { offshore locations. } \\
{ }^{C} \text { Exposed to atmospheres containing salt. }\end{array}$} \\
\hline
\end{tabular}

TABLE $V$

POTENTIAL STATOR WINDING DISCHARGE RISK ASSESSMENT FOR INCREASED SAFETY MOTORS

\begin{tabular}{|l|l|l|}
\multicolumn{2}{c|}{ (IEC 60079-7:2006) } \\
\hline Characteristic & Value & Factor \\
\hline \multirow{3}{*}{ Rated voltage } & $>6.6 \mathrm{kV}$ to $11 \mathrm{kV}$ & 4 \\
& $>3.3 \mathrm{kV}$ to $6.6 \mathrm{kV}$ & 2 \\
& $>1 \mathrm{kV}$ to $3.3 \mathrm{kV}$ & 0 \\
\hline \multirow{3}{*}{ Average starting frequency } & $>1 /$ hour & 3 \\
in service & $>1 /$ day & 2 \\
& $>1 /$ week & 1 \\
& $<1 /$ week & 0 \\
\hline \multirow{3}{*}{ Time between detailed } & $>10$ years & 3 \\
inspections (see IEC & $>5$ to 10 years & 2 \\
60079-17) & $>2$ to 5 years & 1 \\
\hline \multirow{3}{*}{ Degree of protection (IP } & $<2$ years & 0 \\
\hline code) & $<$ IP44 a & 3 \\
& IP44 and IP54 & 2 \\
& IP55 & 1 \\
\hline \multirow{2}{*}{ Environmental conditions } & $>$ IP55 & 0 \\
\hline & Very dirty and wet ${ }^{\mathrm{b}}$ & 4 \\
& Coastal outdoor & 3 \\
& Other outdoor & 2 \\
& Clean outdoor & 1 \\
& Clean and dry indoor & 0 \\
\hline
\end{tabular}


a Only in clean environments and regularly serviced by trained personnel, see 5.2.1. (IEC 60079-7:2006)

b "Very dirty and wet" locations include those that may be subjected to deluge systems or comprise open deck on offshore locations.

In the case of Ex e motors, the stator risk assessment under IEC 60079-7:2006 is informative rather than required. The stator risk assessment factors are shown in Table $\mathrm{V}$. The standard specifies that the user should consider the use of additional measures if the ignition risk factor (i.e. sum total of the factors determined by the table) is greater than 6 , which is exceeded in most practical applications for HV motors.

\section{Risk Assessment - Rotor}

Table VI shows the rotor sparking risk assessment factors for Ex $\mathrm{n}$ motors. Further measures are required if the sum total of the factors determined by the table is greater than 5 a level exceeded by most HV motors in practical applications.

TABLE VI

POTENTIAL CAGE ROTOR SPARKING RISK ASSESSMENT FOR NON-SPARKING MOTORS (IEC 60079-15:2005)

\begin{tabular}{|c|c|c|}
\hline Characteristic & Value & Factor \\
\hline $\begin{array}{l}\text { Rotor cage } \\
\text { construction }\end{array}$ & $\begin{array}{l}\text { Fabricated rotor cage } \\
\text { Cast aluminium rotor cage } \geq 200 \mathrm{~kW} \text { per pole } \\
\text { Cast aluminium rotor cage }<200 \mathrm{~kW} \text { per pole }\end{array}$ & \\
\hline $\begin{array}{l}\text { Number of } \\
\text { poles }\end{array}$ & $\begin{array}{l}\text { 2-pole } \\
\text { 4-pole to 8-pole } \\
\text { > 8-pole }\end{array}$ & $\begin{array}{l}2 \\
1 \\
0\end{array}$ \\
\hline Rated output & $\begin{array}{l}>500 \mathrm{~kW} \text { per pole } \\
>200 \mathrm{~kW} \text { to } 500 \mathrm{~kW} \text { per pole } \\
\leq 200 \mathrm{~kW} \text { per pole }\end{array}$ & $\begin{array}{l}2 \\
1 \\
0\end{array}$ \\
\hline $\begin{array}{l}\text { Radial cooling } \\
\text { ducts in rotor }\end{array}$ & $\begin{array}{l}\text { Yes: } L<200 \mathrm{~mm} \text { (Note 1) } \\
\text { Yes: } L \geq 200 \mathrm{~mm} \text { (Note 1) } \\
\text { No }\end{array}$ & $\begin{array}{l}2 \\
1 \\
0\end{array}$ \\
\hline $\begin{array}{l}\text { Rotor or stator } \\
\text { skew }\end{array}$ & $\begin{array}{l}\text { Yes: > } 200 \mathrm{~kW} \text { per pole } \\
\text { Yes: } \leq 200 \mathrm{~kW} \text { per pole } \\
\text { No }\end{array}$ & $\begin{array}{l}2 \\
0 \\
0 \\
\end{array}$ \\
\hline $\begin{array}{l}\text { Rotor } \\
\text { overhang } \\
\text { parts }\end{array}$ & $\begin{array}{l}\text { Non-compliant (Note 2) } \\
\text { Compliant (Note 2) }\end{array}$ & $\begin{array}{l}2 \\
0\end{array}$ \\
\hline $\begin{array}{l}\text { Temperature } \\
\text { class }\end{array}$ & $\begin{array}{l}\mathrm{T} 1 / \mathrm{T} 2 \\
\mathrm{~T} 3 \\
\geq \mathrm{T} 4\end{array}$ & $\begin{array}{l}2 \\
1 \\
0\end{array}$ \\
\hline
\end{tabular}

NOTE $1 \mathrm{~L}$ is the length of end packet of core. Experimental tests have shown that sparking occurs predominantly in ducts near the ends of the core.

NOTE 2 Rotor overhang parts should be designed to eliminate intermittent contact and to operate within the temperature classification. Compliance with this ruling gives a factor of 0 , otherwise it is 2

The rotor risk assessment factors for Ex e motors specified by IEC 60079-7:2006 are shown in Table VII. Further measures are required if the sum total of the factors determined by the table is greater than 6 , which is the case in most $\mathrm{HV}$ motor applications in practice.

\section{Gas Environment Testing - Stator}

For Ex $\mathrm{n}$ motors, Standard IEC 60079-15 (Paragraph 33.14.2.3) specifies the following steady state ignition test, which is intended to check for sparking during normal operation:

1. Insulation systems and connection cables shall be tested in an explosive gas mixture comprised of (21 $\pm 5) \%$ hydrogen-in-air, v/v with a sinusoidal voltage of 1.5 times the rated r.m.s. line voltage for $3 \mathrm{~min}$. The maximum rate of voltage rise shall be $0.5 \mathrm{kV} / \mathrm{s}$. The voltage shall be applied between one phase and earth with the other phases earthed.

2. No explosion shall occur.

TABLE VII

POTENTIAL CAGE ROTOR SPARKING RISK ASSESSMENT FOR INCREASED SAFETY MOTORS (IEC 60079-7:2006)

\begin{tabular}{|c|c|c|}
\hline Characteristic & Value & Factor \\
\hline $\begin{array}{l}\text { Rotor cage } \\
\text { construction }\end{array}$ & $\begin{array}{l}\text { Uninsulated bar fabricated rotor cage } \\
\text { Open slot cast rotor cage } \geq 200 \mathrm{~kW} \text { per pole } \\
\text { Open slot cast rotor cage }<200 \mathrm{~kW} \text { per pole } \\
\text { Closed slot cast rotor cage } \\
\text { Insulated bar rotor cage }\end{array}$ & $\begin{array}{l}3 \\
2 \\
1 \\
0 \\
0\end{array}$ \\
\hline $\begin{array}{l}\text { Number of } \\
\text { poles }\end{array}$ & $\begin{array}{l}\text { 2-pole } \\
\text { 4-pole to 8-pole } \\
\text { > 8-pole }\end{array}$ & $\begin{array}{l}2 \\
1 \\
0\end{array}$ \\
\hline Rated output & $\begin{array}{l}>500 \mathrm{~kW} \text { per pole } \\
>200 \mathrm{~kW} \text { to } 500 \mathrm{~kW} \text { per pole } \\
\leq 200 \mathrm{~kW} \text { per pole }\end{array}$ & $\begin{array}{l}2 \\
1 \\
0\end{array}$ \\
\hline $\begin{array}{l}\text { Radial cooling } \\
\text { ducts in rotor }\end{array}$ & $\begin{array}{l}\text { Yes: } L<200 \mathrm{~mm} \text { (Note 1) } \\
\text { Yes: } L \geq 200 \mathrm{~mm} \text { (Note 1) } \\
\text { No }\end{array}$ & $\begin{array}{l}2 \\
1 \\
0\end{array}$ \\
\hline $\begin{array}{l}\text { Rotor or stator } \\
\text { skew }\end{array}$ & $\begin{array}{l}\text { Yes: > } 200 \mathrm{~kW} \text { per pole } \\
\text { Yes: } \leq 200 \mathrm{~kW} \text { per pole } \\
\text { No }\end{array}$ & $\begin{array}{l}2 \\
0 \\
0\end{array}$ \\
\hline $\begin{array}{l}\text { Rotor } \\
\text { overhang } \\
\text { parts }\end{array}$ & $\begin{array}{l}\text { Non-compliant (Note 2) } \\
\text { Compliant (Note 2) }\end{array}$ & $\begin{array}{l}2 \\
0\end{array}$ \\
\hline $\begin{array}{l}\text { Limiting } \\
\text { temperature }\end{array}$ & $\begin{array}{l}>200^{\circ} \mathrm{C} \\
135^{\circ} \mathrm{C}<\mathrm{T} \leq 200^{\circ} \mathrm{C} \\
\leq 135^{\circ} \mathrm{C}\end{array}$ & $\begin{array}{l}2 \\
1 \\
0\end{array}$ \\
\hline
\end{tabular}

NOTE $1 \mathrm{~L}$ is the length of end packet of core. Experimental tests have shown that sparking occurs predominantly in ducts near the ends of the core.

NOTE 2 Rotor overhang parts should be designed to eliminate intermittent contact and to operate within the temperature classification. Compliance with this ruling gives a factor of 0 , otherwise it is 2 .

IEC 60079-15 Paragraph 33.14.2.4 describes the required impulse ignition test, which checks for stator discharges in case of voltage transients:

1. Insulation systems and connecting cables shall be tested in an explosive gas mixture comprised of (21 \pm 5 ) \% hydrogen-in-air, v/v. They shall be subjected to 10 voltage impulses of three times peak phase voltage, with a tolerance of $\pm 3 \%$ and with a voltage rise time between $0.2 \mu \mathrm{s}$ and $0.5 \mu \mathrm{s}$, and with a time to half value which is at least $20 \mu \mathrm{s}$ but normally not exceeding $30 \mu \mathrm{s}$. The impulses shall be applied phase-to-phase and separately phaseto-earth.

2. No explosion shall occur

Under IEC 60079-7 Paragraphs 6.2.3.1.3 and 6.2.3.1.4 the corresponding rules for Ex e motors are essentially the same, except that the gas mixtures shown in Table VIII are to be used for the tests. The different test mixtures will also be an option in the next edition of IEC 60079-15.

TABLE VIII

EXPLOSION TEST MIXTURES ( IEC 60079-7)

\begin{tabular}{|l|l|}
\hline Apparatus group & Test mixture in air v/v \\
\hline IIC & $(21 \pm 5) \%$ hydrogen \\
\hline IIB & $(7.8 \pm 1) \%$ ethylene \\
\hline IIA & $(5.25 \pm 0.5) \%$ propane \\
\hline
\end{tabular}


The test requirements for the stator are particularly rigorous in terms of the voltage levels specified. The steady state ignition test is performed with 1.5 times the rated r.m.s. line voltage, while the impulse ignition test is carried out with three times peak phase voltage and the impulses have to be applied phase-to-phase and separately phase-to-earth. The test voltage is measured against ground, whereas in normal running the stress voltage against ground is nominal $/ \sqrt{3}$

The demanding nature of the test is intended to allow for a number of factors, including variations in the supply voltage, manufacturing tolerances, ageing, and contamination.

\section{E. Gas Environment Testing - Rotor}

For Ex $\mathrm{n}$ motors, Standard IEC 60079-15 stipulates in Paragraphs 33.14.1.2 and 33.14.1.3 the following process to simulate rotor cage ageing and the test to check for sparking on starting or stalling:

1. The rotor cage shall be subject to an ageing process comprising a minimum of five locked rotor tests. The maximum temperature of the cage shall cycle between the maximum design temperature and less than $70{ }^{\circ} \mathrm{C}$. The applied voltage shall be not less than $50 \%$ of the rated voltage.

2. After the ageing process the machine shall be filled with, or immersed in, an explosive gas mixture comprised of $(21 \pm 5) \%$ hydrogen-in-air, v/v. Motors shall be subjected to 10 direct-on-line uncoupled starts or 10 locked rotor tests. These tests shall have a duration of at least $1 \mathrm{~s}$.

3. During the tests, the terminal voltage shall not fall below $90 \%$ of the rated voltage. The concentration of hydrogen shall be confirmed after each test.

4. No explosion shall occur.

Under IEC 60079-7 (Paragraphs 6.2.3.2.2 - 6.2.3.2.4) the corresponding rules for Ex e motors are the same, except that the gas mixtures shown in Table VIII above are to be used for the tests.

It is important to note that the tests described above are only representative of operating conditions away from torsional resonance of the complete drive train and where out-of-phase restarting can be excluded - situations which are typical for motors driving high inertia loads or intended to be auto restarted. Such special applications need to be carefully coordinated between the motor manufacturer and the user.

\section{GAS ENVIRONMENT TESTING IN PRACTICE}

Gas environment testing is regarded as a reliable way of verifying that a given design really is non-incendive. However, there are a number of challenges facing the facilities that conduct these explosion tests.

The gases have to be mixed in the correct ratio, and then the concentration maintained within the specified limits throughout the test. The volumes of gas mixture needed for testing the rotors and stators of large machines mean that specialized equipment is necessary.

The high voltages (three times peak phase-to-earth) and special waveforms required also present their own difficulties, and the locked rotor test is demanding in terms of the power needed from the network.

\section{A. Stator Testing}

The winding test procedure will now be described using the example of a $6 \mathrm{kV}$ motor. The first issue to be decided is whether a complete stator or model should be tested, and if a model is tested what are the relevant minimum criteria. Drawbacks to the use of a complete stator could include the high cost and the problem of finding the weak point if an ignition does occur.

If a model is used it must be representative of the complete winding system. Therefore a minimum of 2 phases are necessary and a sufficient number of coils should be used to reflect a segment (upper and lower coils to be integrated in one slot). To allow the phases to be tested separately they should be open and not connected. The model must also provide a realistic representation of the mounting of RTDs and other devices, it should reflect the critical distances between the winding and the frame, and possibly also the rotor. The way in which the cable connecting the winding to the terminals is installed is also important.

The order in which the sinusoidal and impulse tests are performed is not important. If plastic film is used to contain the test sample and gas atmosphere, an ignition will not destroy the winding and a number of tests can be performed using one sample. See Fig. 4.

The first step in the sinusoidal test is to ground the frame and all phases which are not undergoing testing. One phase is connected to the high voltage supply. A $6 \mathrm{kV}$ machine is tested with $9 \mathrm{kV}$. After the first phase has been tested for 3 minutes the same procedure is repeated on the second phase. Failure of one phase naturally means that the test as a whole is failed. Experience has shown that ignition does not necessarily occur at the beginning of the test, and an explosion can occur at the end of the 3 minute period.

The impulse test has to be performed under the same conditions as the sinusoidal test with respect to grounding. The polarity for the test should be chosen, and there is no direct need to test both polarities. The voltage level is 6 $\mathrm{kV}^{*} \sqrt{2}{ }^{*} \sqrt{3}=14.7 \mathrm{kV} .10$ impulses are applied to the 2 phases and no explosion should occur. Note that explosions do not necessarily occur on the first pulse.

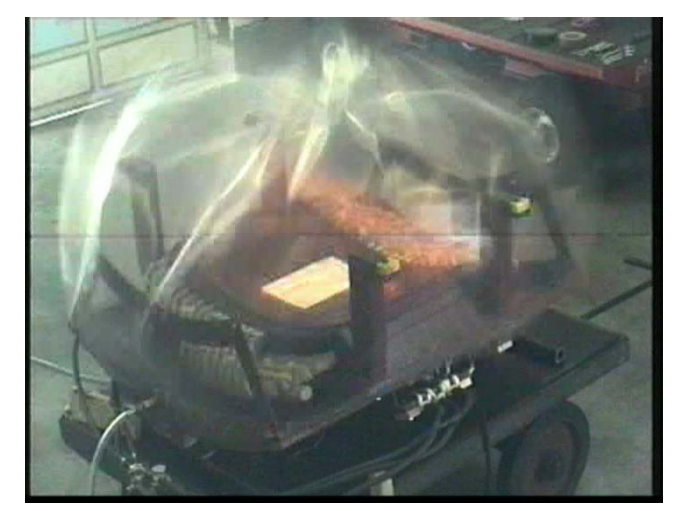

Fig. 4. A stator sample undergoing testing. The gas has been ignited by sparking. (Photograph courtesy of Notified Body)

\section{B. Rotor Testing}

With regard to the rotor, the ageing process requires that the rotor temperature is measured at the hottest point. If the manufacturer cannot specify where the hottest point is then testing is performed using the least favorable conditions, 
which can negatively impact the result of the tests. Fig. 5 . shows a rotor gas environment test.

Note that the rotor test provides two options - either direct-on-line uncoupled starts or locked rotor tests. These options are provided because it is not practical to perform the starting test for large rotors, and so the stalling test can be used instead as it is considered to represent a reasonable equivalent.

Even though gas environment testing is challenging, it is well within the capabilities of specialized testing laboratories. By following the correct procedures, the testing process can be conducted in safety, despite the presence of hazardous gases. Several motor manufacturers have already had their products tested.

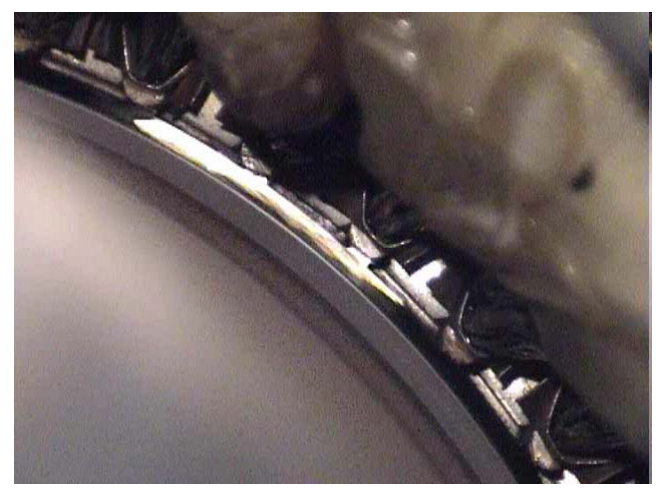

Fig. 5. Sparking during a rotor test. (Photograph courtesy of Notified Body).

\section{OPTIONS AVAILABLE UNDER THE STANDARDS}

When sourcing Ex $\mathrm{n}$ and Ex e motors for use in hazardous areas, the main options for the end user are (1) to specify that the motors have been gas tested and certified or (2) perform a risk assessment. In the latter case, if the factor threshold level is exceeded then the motor will generally have to be equipped with provision for pre-purging. This will require a higher capacity air compressor, piping, and a purge control unit. Purging has to be performed every time the motor is started and it naturally prolongs the starting operation.

\section{A. Gas Testing And Certification}

Specifying motors that have been gas environment tested and certified provides a number of benefits for the end user or operator. Certification confirms that sparking is minimized according to the requirements of the relevant international standards. With certified motors, the manufacturer is responsible for delivering safety independently - i.e. the information needed for the risk assessment process is not required. As there is no risk assessment, there is no need for the end user to be concerned about any changes in factors such as starting procedures, maintenance regimes, or environmental conditions over the lifetime of the motor.

Unlike the case of pre-start purging, there is no onus of responsibility on the end user - the manufacturer is solely responsible for the safety of the motor (there is an exception to this, however; in the case of Ex e motors rated $6 \mathrm{kV}$ and over where the stator risk factors are exceeded, pre-start purging may be required in addition to gas environment testing).
Another advantage of certified motors is that the manufacturer has to ensure they are free of stator PDs in order to pass the gas environment test. As PDs erode the insulation and shorten the lifetime of the stator winding, the elimination of PDs translates into higher overall reliability.

\section{B. Risk Assessment}

The risk assessment option involves a number of problems which can be grouped into three main categories: lack of information flow, changing specifications, and varying conditions during the machine's lifetime.

The risk assessment process requires cooperation between the manufacturer and end user. In particular, the end user has to supply information on factors such as starting frequencies, maintenance intervals and environmental conditions to the manufacturer. The nature of the motor supply chain in many projects, however, means that the communications channel between the manufacturer and end user runs via OEMs (who supply pump or compressor packages, for example) and EPC (engineering, procurement and construction) contractors. As a result it can be difficult for the manufacturer to get the necessary information.

Even in cases where there are effective channels of communication and the necessary information is available, the risk assessment may have to be performed several times. This is because requirements tend to be somewhat 'fluid' during the quotation phase and motor specifications especially regarding speed and power - are often subject to change.

Finally, once the motor has been installed, the circumstances in which it operates may well change over its lifetime. Any change in factors such as the starting frequency, maintenance interval, or environmental conditions will naturally render the motor's certification invalid.

\section{Provision For Pre-Purging When Risk Factors Exceeded}

Where a risk assessment is undertaken and the risk factors are exceeded, the most common option is the provision for pre-purging. In practice this means that the motor is fitted with flanges to allow connection of a compressed air line for pre-start purging with instrument air.

For the manufacturer, this is a very favorable solution: it is easy to provide and also transfers responsibility for safety in operation to the end user or operator. This is because it is left to the end user or operator to decide whether or not to perform purging. Safety managers naturally seek to minimize risk and therefore insist that purging is incorporated into the starting procedures.

There are a number of drawbacks to this solution for the end user or operator. It significantly increases the time taken to start the motor: it has to be purged every time it is started, and this can take 10 minutes for a cast iron motor and 25 60 minutes for a large modular unit (approximate times). It requires capital expenditure in the form of higher compressor capacity, piping, and a purge control unit, and it increases operating expenses through the need to run and maintain the compressor. Overall reliability is reduced as the additional equipment required for purging could fail.

Another major disadvantage to pre-start purging is that it does not effectively address the problem of stator PDs. If stator PDs are present, they are present all the time - not just on starting. While purging will minimize the risk of gas pockets inside the motor enclosure on starting, it does not prevent the ingress of gas during operation. For this reason 
IEC 60079-7:2006 requires a stator gas test for all Ex e motors rated $1 \mathrm{kV}$ or higher, and the same requirement will be included in IEC 60079-15:20XX , i.e. the next version of the standard applying to Ex $n$ motors.

Rotor sparking, by contrast, is by nature most likely to occur on starting. Therefore pre-start purging is an effective means of minimizing the risk that gas inside the motor could be ignited by sparks from the rotor.

\section{CONCLUSIONS}

This paper has demonstrated the process by which incidents involving electrical machines have influenced the development of the relevant standards. The work that has been done has resulted in the implementation of major safety improvements in the standards.

The safe use of large electrical machines in hazardous areas requires the involvement of both the manufacturer and end user. Gas environment testing, which is the only way to verify that a given design is completely safe, is the responsibility of the manufacturer. End users have the option of performing a risk assessment (and undertaking prepurging if the risk factors are exceeded), but this approach requires a lot of effort on the part of the users and still does not result in maximum safety.

There are clearly important benefits for end users in specifying motors that have been gas tested and certified for both the rotor and stator.

\section{REFERENCES}

[1] "Possible risks associated with the use of explosionprotected motors types Ex ' $N$ ' and Ex 'e'" Operational Circular OC 498/12 (REV) and associated Information Document, Health and Safety Executive, Field Operations Division, 1995.

[2] "Report on an investigation by UK manufacturers of large electrical machines into problems of electrical motors of type Exe and ExN operating in potentially explosive atmospheres" London, UK: Rotating Electrical Machines Association, 1990.

[3] "Electric motors for use in hazardous areas" Safety Notice PED 5 17/90, Department of Energy, October 1990.

[4] "A Guide to Risk Based Assessments of Large Insitu Ex ' $e$ ' and Ex ' $N$ ' High Voltage Machines" Publication No. 181, London, UK: Engineering Equipment and Materials Users Association (EEMUA), 1995.

[5] Von Pidoll, U. Brzostek, E. Froechtenigt, H.-R Determining the incendivity of electrostatic discharges without explosive gas mixtures. IEEE Transactions on Industry Applications, Vol 40, Issue 6, pp 1467- 1475, 2004.

[6] IEC 60034-18-41 "Rotating electrical machines Part 18-41: Qualification and type tests for Type I electrical insulation systems used in rotating electrical machines fed from voltage converters" Geneva, CH: IEC 2006-10-11.

[7] IEC 60079-7:2006 Ed. 4 "Explosive atmospheres Part 7: Equipment protection by increased safety ' $e$ "' Geneva, CH: IEC.

[8] CENELEC, ENV 50269:1997, "Assessment and representative testing of high voltage machines" Brussels, B: CENELEC.

[9] CENELEC, EN 50021 "Electrical Apparatus for Potentially Explosive Atmospheres - Type of
Protection 'n'” Brussels, B: CENELEC 1999-04

[10] CENELEC, EN 60079-15:2003 "Electrical apparatus for explosive gas atmospheres - Part 15: Type of protection ' $n$ '” Brussels, B: CENELEC.

[11] Directive 94/9/EC "Equipment intended for use in potentially explosive atmospheres (ATEX)" European Parliament and Council, 1994.

[12] IEC 60079-14 Ed. 4.0 b:2007 "Explosive atmospheres - Part 14: Electrical installations design, selection and erection" Geneva, $\mathrm{CH}$ : IEC.

[13] IEC 60079-15:2005 "Electrical apparatus for explosive gas atmospheres - Part 15: Construction, test and marking of type of protection ' $n$ ' electrical apparatus" Geneva, CH: IEC.

[14] CENELEC, EN 60079-15:2005 "Electrical apparatus for explosive gas atmospheres - Part 15: Construction, test and marking of type of protection " $n$ " electrical apparatus" Brussels, B: CENELEC.

[15] CENELEC, EN 60079-7:2007 "Explosive atmospheres - Part 7: Equipment protection by increased safety ' $e$ '” Brussels, B: CENELEC.

\section{VITA}

Jussi Rautee graduated with an M.Sc. in Electrical Engineering from Tampere University of Technology in Finland. He has been with ABB for 10 years, and has held positions in product development, product management and sales. He is presently Global Market Manager (Chemical, Oil and Gas Industries) for medium and high voltage motors and generators. He is a member of the IEEE and of IEC TC 31 WG 27 "Explosion-Protected Electrical Machines".

Frank Lienesch is a graduate of the University of Braunschweig in Germany. Since 1994 he has been working in the field of explosion-protected electrical machines at the Physical-Technical Institute of Germany (a Notified Body). $\mathrm{He}$ is a member of IEC TC 31 WG 27 "Explosion-Protected Electrical Machines".

Tom Liew graduated with a degree in Electrical Engineering from the University of Wales in 1973. After working in electronic research he joined the Shell Group of Companies. He was Project Engineer in Brunei, then Chief Electrical Engineer at the Shell UK refinery in Essex, and later Group Adviser for the Far East at Shell in The Hague, Netherlands. In 1995 he was appointed Chief Electrical Engineer of the LNG Plant in Brunei, then in 2002 moved to Aberdeen, Scotland, as Discipline Head for Shell EP Europe. $\mathrm{He}$ is now based in Houston, Texas, as Electrical Lead for the Port Arthur refinery project. He is a Fellow of the IET and a previous member of IEC TC 31. 